\title{
Prediction of Pitting Corrosion Characteristics using Artificial Neural Networks
}

\author{
Haider M. Mohammad, \\ $\mathrm{PhD}$. \\ Dept. of Materials Engineering \\ University of Basrah- Iraq
}

\author{
Nawal J. Hammadi, PhD. \\ Dept. of Materials Engineering \\ University of Basrah- Iraq
}

\author{
Rafil M. Lafta, PhD. \\ Dept. of Materials Engineering \\ Dept. of Mechanical \\ Engineering \\ University of Basrah- Iraq
}

\begin{abstract}
Precorroded steel A-106 B specimens were prepared at different surface roughness. These specimens were immersed in corrosive ferric chloride solution in different concentrations $(1.5,3.0,4.5,6.0 \%$ wt.) at specified durations to initiate primarily the pitting corrosion. The corrosion pits distribution depend on the corrosive concentration, degree of surface roughness, and immersion duration. The pits were characterized using metallurgical microscope. Also, The pitting characteristics aimed to be predicted by "Artificial Neural Networks" (ANNs). The results obtained of pit quantification by ANNs predictions are shown to be agreed well against experimental values. i.e. R2 $=0.9839$
\end{abstract}

\section{Keywords}

Pitting corrosion, Artificial neural network, ANN; and surface roughness

\section{INTRODUCTION}

The presence of corrosion is known to reduce the failure resistance of materials. Pitting is one of the most destructive and insidious form of corrosion, it causes equipment to fail because of perforation [1,2]. A common observation agreed upon by many researchers [2-5] was that the presence of pitting frequently associated with significant fatigue life reduction, due to crack originating from corrosion pit.

It was stated that corrosion in general is a stress raiser that can lead to fatigue cracking, with pitting being especially detrimental [6].

The assessment of deleterious effect of pitting on structure's fatigue performance is through quantification of pitting. This has implies, the size, density and morphology of corrosion pits. The corrosion product inside pitting damage can be a further confounding influence in measurement efforts. Several techniques have been employed for pit measurements such as roughness measurement [6,7], microscopy [8,9], and electrochemical such as impedence measurements.

Practically a sectioning method followed by image analysis was successfully used by Codaro et al. [10] for pit examination using SEM \& TEM.

The present work is a part of a comprehensive work concerned with computational method in mechanics of fracture. The experimental study deals with the preparation of pre-corroded specimens throughout pit initiation arbitrarily on steel A-106 B which were then subjected to fatigue test. An attempt to quantify the corrosion pit by "Artificial Neural Networks" was carried out. The method for pitting quantification with several experimental observations will be used in the future adaptation of the proposed life prediction for the pitted material under investigation.

\section{EXPERIMENTAL WORK}

\subsection{Specimen Preparation}

The specimens were prepared initially from solid bar (length $30 \mathrm{~cm}$, diameter $12 \mathrm{~mm}$ ). The diameter was reduced by "Turning Machine" to $8.0 \mathrm{~mm}$. The bar is then cut into 50 pieces each of $147 \mathrm{~mm}$ length as shown in plate (1) below.

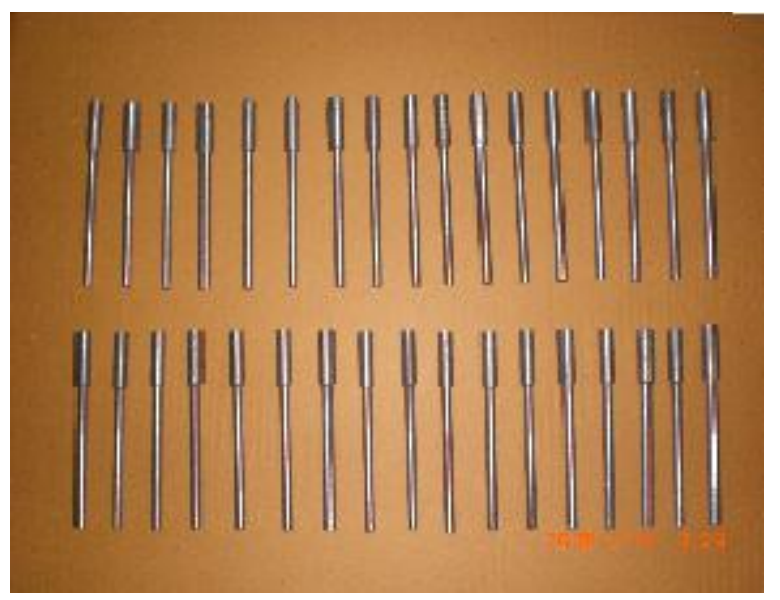

Plate 1: Specimens of the present experimental study

The chemical composition of the solid bar (Steel A106-B) given by ASTM Standard Specification [11]: (max $0.3 \% \mathrm{C}$, $0.29-1.06 \% \mathrm{Mn}, \max 0.035 \% \mathrm{P}, \max 0.035 \% \mathrm{~S}, \min 0.10 \% \mathrm{Si}$, $\max 0.40 \% \mathrm{Cr}, \max 0.40 \% \mathrm{Cu}, \max 0.15 \%$ Molybdenum, max $0.40 \% \mathrm{Ni}$, max $0.08 \% \mathrm{~V}$ ).

\subsection{Surface Preparation}

The specimens were subjected to different degrees of surface finish. Each specimen was ground by certain grit emery paper to produce different degrees of surface roughness. The measurements of surface roughness were performed using surface roughness tester (Plate 2) portable-type (Qualitest TR110 , US) in terms of surface roughness factor Ra in $(\mu \mathrm{m})$, for 50 specimens. 


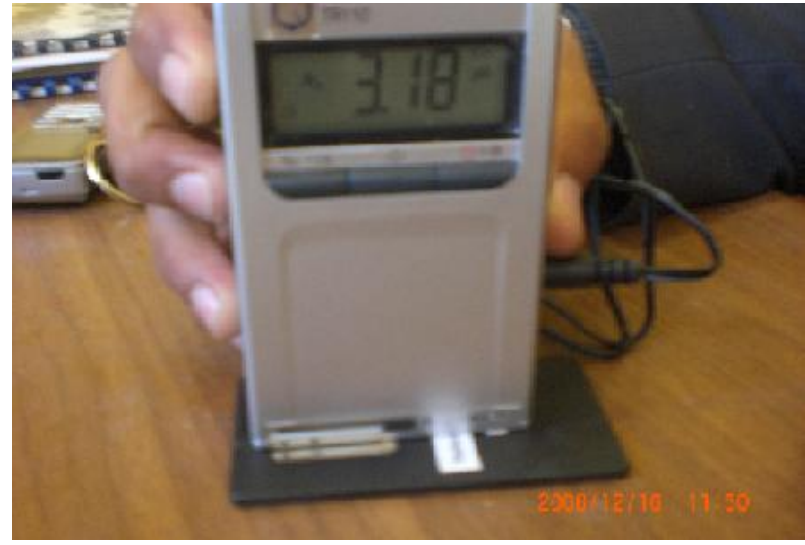

Plate 2: Portable Surface Roughness Tester

The prepared specimen surfaces with different surface roughness factor were utilized for precorrosion stage. For instance, rough surface corrodes and enhances pitting corrosion more readily than smooth surface [3].

\subsection{Pit Initiation}

The freshly prepared specimens with the specified surface area of $(20 \mathrm{~cm} 2)$ were subjected to corrosion prior to fatigue loading or (prior to fracture experiment) as this work is a part of extended research on special type of fatigue fracture mechanics. The corrosion process involved immersion in different concentration of corrosive ferric chloride (1.5, 3.0, $4.5,6.0 \%$ wt.) at a temperature of $27 \pm 2 \mathrm{oC}$, within a specified duration period of $48,96,144 \& 192$ hours in each individual concentration. After the specimens had been corroded, the corrosion pits were characterized using metallurgical microscope (Olympus, Japan). The numbers of pits per unit area were determined as pitting density (PD). The most important was the pit depths (pd), which were determined according to the standard method given by ASTM G46-95 $[12,13]$.

There are many factors concerned with corrosion pit as pit density, pit depth, pit proximity, pit geometry and pit surface area. The treatment of specimens with ferric chloride is to initiate pitting corrosion under the effect of aggressive chloride ions.

The goal of the pre-corrosion testing was to determine how pitto-crack transition occurs when the specimens are subjected to cyclic loading.

However, the present work concern with: a) measurements of pitting density and pitting depth by laboratory testing method, and b) using ANNs [14-16] to predict both of these characteristics.

\section{NEURAL NETWORK ARCHITECTURE}

In this work neural network is used for prediction pitting density and pit depth in different concentration of ferric chloride, immersion duration, and roughness factor.

The architecture of neural network for this study is given in Figure 3. It consists of three nodes in the input layer, two hidden layers were chosen while it gives minimum mean square error (MSE), the first hidden layer has (16) nodes, and the second hidden layer has (9) nodes. The output layer has two nodes which represent pitting density, and pit depth.

The decision function used for both of the first hidden layer and for second hidden layer is (tansig), and for the output layer is (purelin). These functions were chosen for first hidden, second hidden and the output was obtained by trial and error until the best performance was achieved by approaching the minimum values of mean square error.

The training was done after obtaining the experimental results, which was used to train the neural networks using 40 data out from 50 data of the experiment results, the remaining 10 data will be used for testing the trained neural network.

This neural network simulation is done by "MATLAB R2007A".

\section{RESULTS AND DISCUSSION}

The treatment of specimens with ferric chloride is carried out to initiate corrosion pits under the effect of aggressive chloride ions at static condition and normal temperature. Thus, these precorroded specimens were then used for further study for pitto-crack transition experiment which will be presented in future publication. The presence of pits considered as crack origin [6,13].

The initiated pits under different concentration of corrosive chloride, at specified immersion durations and different roughness factors were identified and characterized by laboratory test experiment.

\subsection{Laboratory Experiment}

The experimental results showed evidently that the corrosion pit growth increases with the increase of corrosive concentration of 1.5, 3.0, 4.5, 6.0\% wt. and with increase of immersion duration in terms of pitting density (PD) and pit depths (pd) respectively. Also, the degree of roughness in term of roughness factor enhances the progress of (PD) \& (pd) respectively i.e. an increase of the roughness factor $(\mathrm{Ra})$ resulted in further growth of corrosion pits. Since rough surface corrodes more readily than smooth surface [3].

However, the maximum (PD) and (pd) values at maximum duration (192 h.), maximum corrosive concentration $6.0 \%$ wt./v. and with maximum roughness factor $(\mathrm{Ra}=15 \mu \mathrm{m})$ were found $6.99 \mathrm{pit} / \mathrm{cm} 2$ and $2.45 \mathrm{~mm}$ respectively.

\subsection{Artificial Neural Networks}

The proposed structure of ANNs is presented in Fig. 1. The prediction of pitting density and pit depth within the experimental values of different corrosive concentrations, immersion durations and roughness factor were determined and verified.

The results predicted by artificial neural networks showed a reasonable agreement with R2 $=0.9839$ as shown in Fig. 2

Two sets of data were presented by ANNs:

First, (a) pitting density with different roughness factor at different corrosive concentrations as shown in Fig. 3. (b) pitting depth with different roughness factor at different corrosive concentrations as shown in Fig. 4. In these figures, pitting density and pitting surface depth increased directly with the increase of both roughness factor and corrosive concentrations.

Second, (a) pitting density with different roughness factor at different immersion durations as shown in Fig. 5. (b) pitting depth with different roughness factor at different immersion duration as shown in Fig. 6. Also, pitting density and pitting 
depth increased directly with increasing of roughness factor and immersion duration.

The prediction of pitting corrosion behavior can be best described using three sets of histograms: (a) pitting density with corrosive concentration at different roughness factor $(6,9$, $12,15 \mu \mathrm{m})$ as shown in Fig.7 at immersion durations of (48, $96,144 \mathrm{~h}$.), (b) pitting depth with corrosive concentration at different roughness factor $(6,9,12,15 \mu \mathrm{m})$ as shown in Fig. 8 at immersion duration of $(48,96,144 \mathrm{~h}$.). The results showed that pitting density and pit depth increased with increasing corrosive concentrations. Moreover, (c) pitting density and pitting depth at different immersion duration at $\mathrm{Ra}=8.0 \mu \mathrm{m}$ as shown in Figs. 9 \& 10 respectively. Therefore, increasing immersion duration increase pitting density and pitting depth.

However, the results of 192 hour immersion duration were not presented, because of limiting value of corrosion parameters observed in such prolonged immersion duration.

Future work should include study of the combined effect of pit proximity and pit surface area with pit density and depth on the transition to fatigue cracking.

\section{CONCLUSIONS}

1. The artificial neural networks results were found well agreed with that obtained by laboratory test.

2. Increase of corrosive concentrations with extended immersion duration resulted in an increase of pitting density and pitting depth.

\section{REFERENCES}

[1] Dooley, E.J., Lee, B., and Wei R.P. 2000. The effect of pitting corrosion on fatigue life. Fatigue Fracture Eng. Mat. Struct. 23, pp 555-560.

[2] Sankaran, K.K., and Jata, K.V. 2001. Effect of pitting corrosion on fatigue behaviour. modeling and experimental studies, Mat. Sci. Eng. A297, P 223.

[3] Frantziskonis, G.N., Simon, L.B., Woo. J., and Matikas. T.E. 2000. Multiscale characterization of pitting corrosion and application. Eur. J Mech. A-Solid 19, pp 309-318.

[4] Chen, G.S., Lia, C.M., Wan, K.C., Gao, M., and Wei, R.P. 1997. Pitting corrosion \& fatigue crack nucleation in: Effect of environment on initiation of crack growth. ASTM 1298, Am. Soc. For Tesing \& Material, pp 18-31.

[5] Piascik, R.S., and Willard, S.A. 1994. The growth of small corrosion fatigue crack. Fatigue Fracture Engg. Mat. Structure 17 (11), pp 1247-1259.

[6] Van der Walde, Brokenbrough, J.R., Craig, B.A., and Hillberry. 2005. Multiple fatigue crack growth in precorroded alloy. Int. J Fatigue 27, pp 1509-1518.

[7] Johnes, K. 2004. Effect of microstructure on pit-to-crack transition of Al-alloys. Phd thesis, Univ. of Utah.

[8] Perez, R. 1996. Corrosion/Fatigue Metrics In: Proc. of ICAF 97 Symp on Fatigue in New and ageing aircraft. Edinburgh, Scotland, pp 215-290.

[9] Tue gel, E. J. 2003. Investigation of the effect of corrosion pits on fatigue life of Al-structure. Rpt. AFL-VA-WP-TR (2003), AFR Lab., Wright-Potterson, Ohio.

[10] Codaro, E.N., Nakazato, R.Z., Horovistiz, A.L., Ribeiro, L.M.F., Ribeiro, R.B., and Hein, L.R.D. 2002.
Characterization \& evaluation of pitting corrosion. Mat Sc. Eng. A334, pp 298-306.

[11] ASTM International. 2008. Standard Specification for seamless carbon steel pipe for high-temperature service.

[12] Standard Guide for Examination and Evaluation of Pitting Corrosion. ASTM 2005.

[13] Van Der Sluys, Piascik, R.S., Zawierucha, R. 1997. Effect of the environment on the initiation of crack growth. ASTM STP 1298, ASTM 1997.

[14] Rojas, R. 1996. Neural Networks: A Systematic Introduction. Springer.

[15] Baughman, D.R. and Liu, Y.A. 1995. Neural Network in Bioprocessing and Chemical Engineering. Academic Press, San Diego, CA.

[16] Simpson, P. 1990. Artificial Neural Systems: Foundations, Paradigms, Applications and Implementations. Pergamon Press, New York, N.Y.

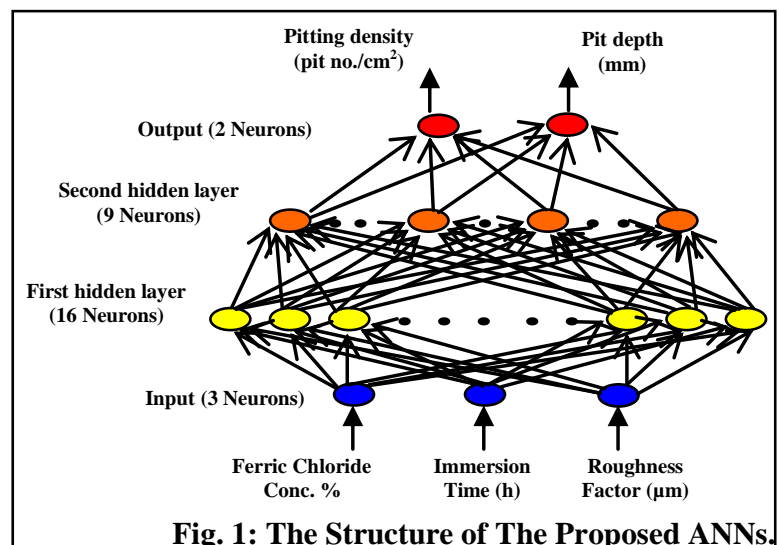

Fig. 1: The Structure of The Proposed ANNs.

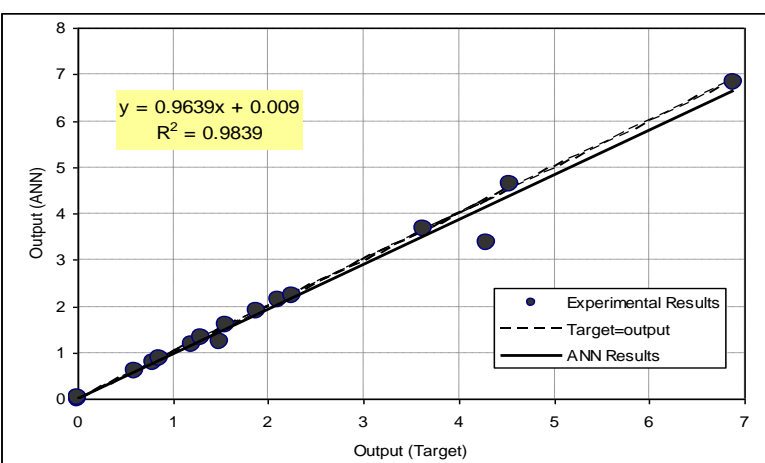

Fig 2: Comparison between ANN Results using Resilliant Backpropagation Algorithm 


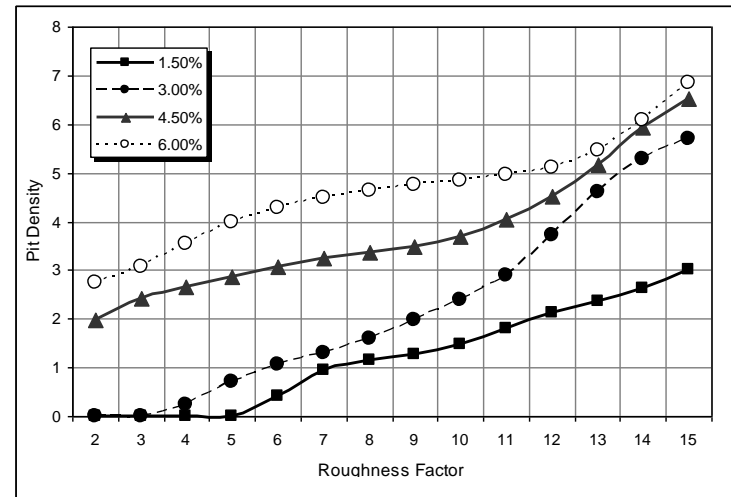

Fig. 3: Pitting density with roughness factor at 144 hour immersion duration

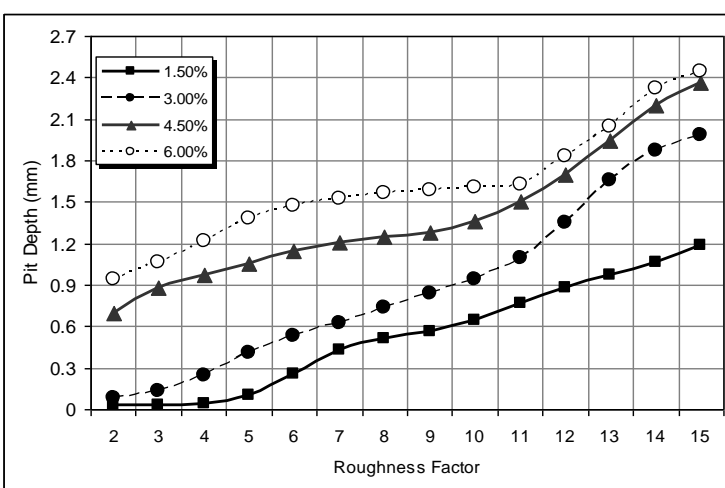

Fig. 4: Pit depth with roughness factor at 144 hour immersion duration

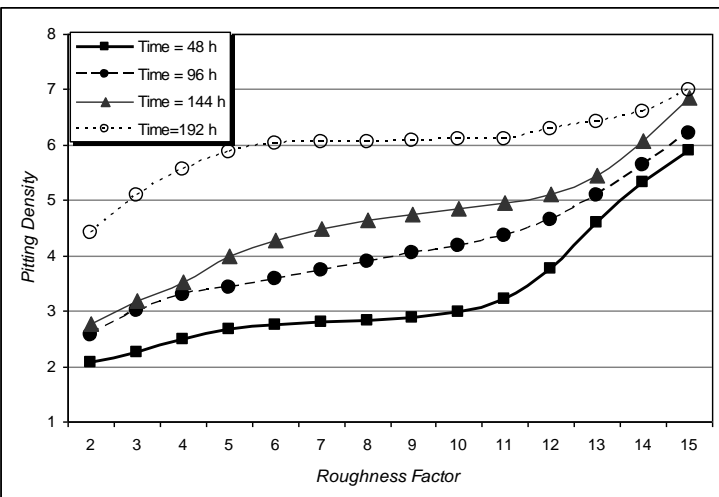

Fig. 5: Pitting density with roughness factor at $6 \%$ ferric chloride concentration

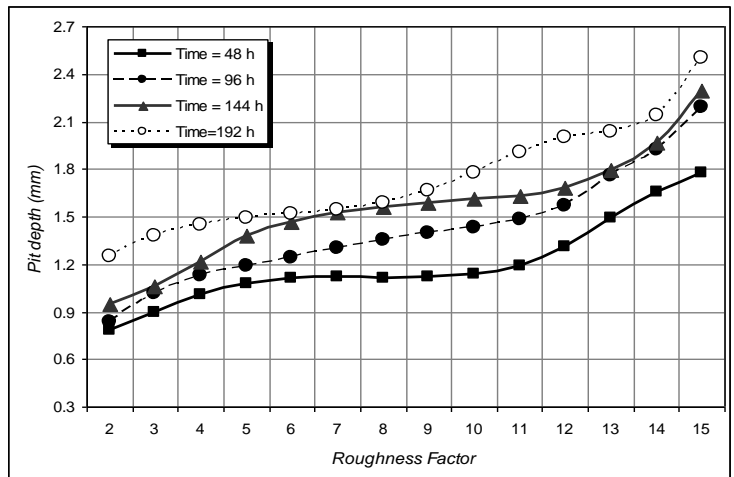

Fig. 6: Pit depth with roughness factor at $6 \%$ ferric chloride concentration

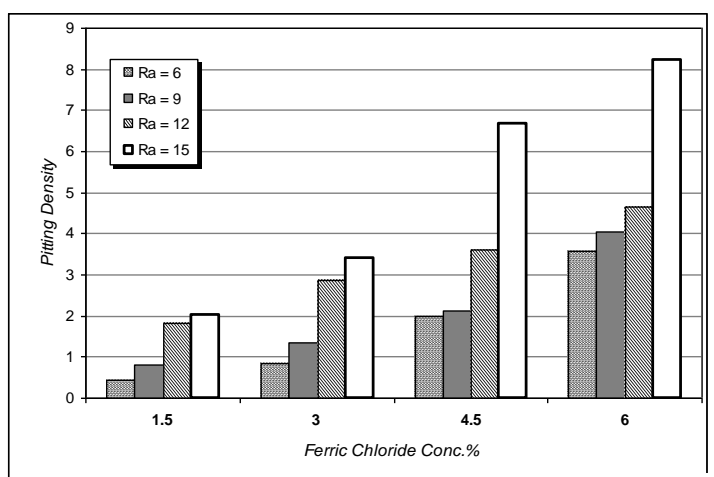

Fig. 7: Pitting density with ferric chloride conc. at different roghness factor with $96 \mathrm{hr}$.

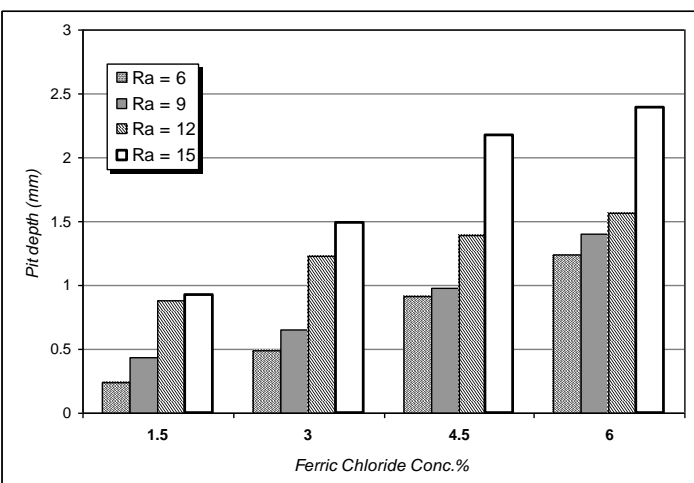

Fig. 8: Pit depth with ferric chloride conc. at different roghness factor with $96 \mathrm{hr}$. 


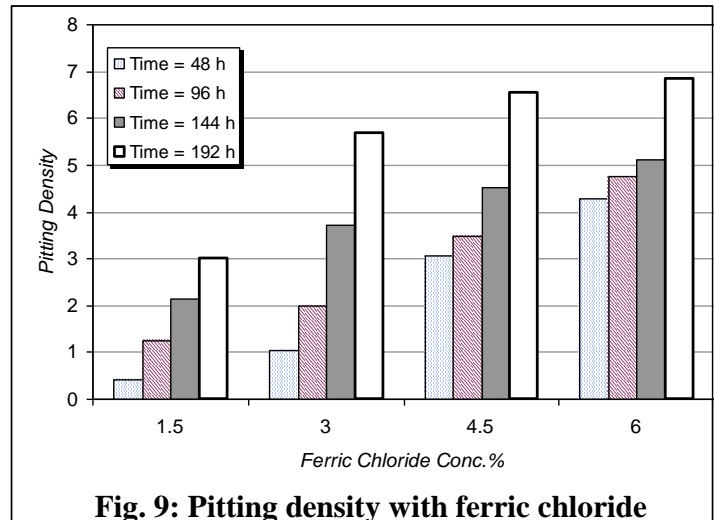
conc. at different values of immersion

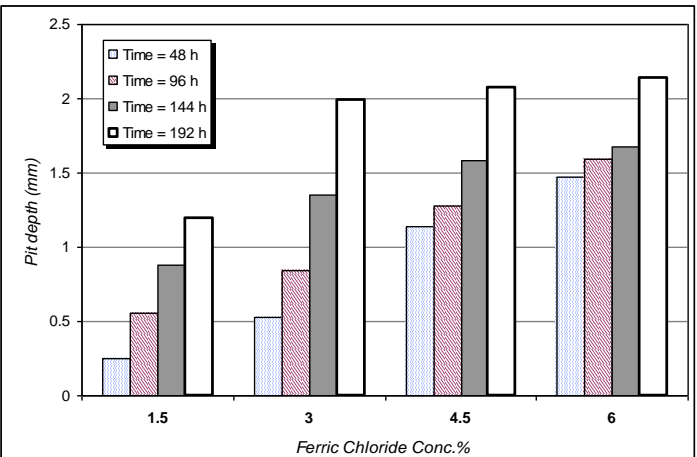

Fig. 10: Pit depth with ferric chloride conc. at different values of immersion duration 